\title{
Assessing PAC contribution to the NOM fouling control in PAC/UF systems
}

\author{
Margarida Campinas ${ }^{a, b, *}$, Maria João Rosa ${ }^{b}$ \\ ${ }^{a}$ University of Algarve, Gambelas Campus, 8005-139 Faro, Portugal \\ ${ }^{\mathrm{b}}$ Urban Water Division, Department of Hydraulics and Environment LNEC - National Laboratory for Civil Engineering, Av. Brasil 101, 1700- \\ 066 Lisboa, Portugal
}

\section{A R T I C L E I N F O}

\section{Article history:}

Received 17 April 2009

Received in revised form

28 September 2009

Accepted 9 November 2009

Available online 14 November 2009

\section{Keywords:}

NOM

Algogenic organic matter

PAC

UF

Membrane fouling

\begin{abstract}
A B S T R A C T
This paper investigates the powdered activated carbon (PAC) contribution to the fouling control by natural organic matter (NOM) in PAC/UF hybrid process, as well as the foulant behaviour of the PAC itself. Solutions of NOM surrogates (humic acids, AHA, and tannic acid, TA) and AOM/EOM (algogenic organic matter/extracellular organic matter) fractions from a Microcystis aeruginosa culture were permeated through an ultrafiltration (UF) hollowfibre cellulose acetate membrane (100 kDa cut-off). The greatest impairment on flux and the poorest rejection were associated with polysaccharide-like EOM substances combined with mono and multivalent ions. PAC, either in the absence or in the presence of NOM, did not affect the permeate flux nor the reversible membrane fouling, regardless of the NOM characteristics (hydrophobicity and protein content) and water inorganics. However, PAC controlled the irreversible membrane fouling, minimising the chemical cleaning frequency. Furthermore, PAC enhanced AHA and TA rejections and the overall removal of $\mathrm{AOM}$, although it was apparently ineffective for the highly hydrophilic EOM compounds.
\end{abstract}

(c) 2009 Elsevier Ltd. All rights reserved.

\section{Introduction}

Natural organic matter (NOM) negatively impacts the efficiency of several water treatment processes, is the major precursor of disinfection by-products, and is responsible for tastes, odours and bacterial re-growth in the distribution system. NOM is usually not significantly removed by ultrafiltration (UF), but is a major contributor to membrane fouling, which is one of the critical issues in membrane technology application for water and wastewater treatment.

NOM fouling mechanisms are gel formation (an extreme case of concentration-polarisation), cake formation, pore blockage and pore constriction. Concentration-polarisation has weaker effects than pore blockage and surface deposition (Cho et al., 2000; Yuan and Zydney, 2000). Of particular importance is the size distribution of the feed solution components relative to the membrane pore size. Foulants smaller than the membrane pores may adsorb on the porous surface and lead to pore constriction, while larger components may block the pore entrances and contribute to cake or gel formation on the membrane surface (Costa et al., 2006).

The understanding of which NOM components are responsible for membrane fouling has been a worldwide research issue in the membrane field. Researchers used sophisticated separation and analytical techniques to characterise NOM during membrane runs or through membrane autopsies, focusing on NOM molecular size, hydrophilicity/ hydrophobicity and functional group analysis. Several researchers suggested that, among the different NOM molecular size fractions, the colloidal fraction causes the most

\footnotetext{
* Corresponding author. Urban Water Division, Department of Hydraulics and Environment LNEC - National Laboratory for Civil Engineering, Av. Brasil 101, 1700-066 Lisboa, Portugal. Tel.: +351 218443617; fax: +351 218443032.

E-mail addresses: mgd.campinas@gmail.com (M. Campinas), mjrosa@lnec.pt (M.J. Rosa). 0043-1354/\$ - see front matter @ 2009 Elsevier Ltd. All rights reserved. doi:10.1016/j.watres.2009.11.012
} 
significant flux decline (Schäfer et al., 2000; Costa et al., 2006; Lee et al., 2006). Others have demonstrated the strong foulant behaviour of the humic substances (Jones and O'Melia, 2000; Yuan and Zydney, 2000) or the leading role of the hydrophilic neutral NOM fraction (polysaccharides, proteins, amino sugars) on low-pressure membrane (microfiltration/ultrafiltration) fouling, particularly the irreversible one (Cho et al., 2000; Lee et al., 2006; Yamamura et al., 2007).

In addition, when treating algal rich-waters, NOM includes algogenic organic matter (AOM) whose intracellular fraction has shown a nanofiltration fouling behaviour (Her et al., 2004). Earlier UF studies for cyanobacteria and cyanotoxins removal from drinking water (Campinas, 2009) indicated the need of UF performance enhancement by a process able to simultaneously control the dissolved toxins and minimise the membrane fouling exerted by the extracellular fraction (EOM) of AOM in the presence of background multivalent ions.

Powdered activated carbon (PAC) in combination with UF is a promising water treatment option, particularly when seeking the safe control of cyanobacteria and associated toxins. UF is a safe barrier against cyanobacteria and PAC is efficient for microcystin removal (Campinas, 2009) and is able to compete with the membrane for the NOM compounds, thus reducing NOM adsorption on the membrane surface and/or pores. There are however contradictory results concerning the PAC effect on the membrane fouling. Some authors reported an improvement of permeate flux, longer filtration runs or a reduced frequency of chemical washing (Adham et al., 1991; Konieczny and Klomfas, 2002; Lee et al., 2007). Others presented similar flux behaviour (Yiantsios and Karabelas, 2001; Tomaszewska and Mozia, 2002; Matsui et al., 2006) or exacerbated flux decline (Lin et al., 1999; Li and Chen, 2004; Zhao et al., 2005; Zularisam et al., 2007).

The PAC effect on membrane fouling seems to be a function of the membrane characteristics, namely its hydrophobicity. The studies of Crozes et al. (1993), Lin et al. (2001) and Mozia et al. (2005) showed that PAC reduced or did not affect the flux decline of hydrophilic membranes, but it was not effective or worsened the flux of the hydrophobic membranes. Raw water diversity is also often used to explain the contradictory PAC effects on membrane fouling, although there is a lack of studies on this subject.

For that matter, the main purpose of this study is to investigate the PAC contribution to the fouling control of an UF hydrophilic membrane. The effects of different NOM characteristics on the performance (fluxes and rejections) of the PAC/UF hybrid process are addressed. Algogenic organic matter is included as NOM surrogate since a fairly new application of PAC/UF process is envisaged - the control of cyanobacteria and associated toxins in drinking water.

\section{Materials and methods}

\subsection{NOM solutions}

Commercial humic acid (AHA, Aldrich Chemicals) and tannic acid (TA, Sigma, ca. $1700 \mathrm{Da}$ ) were chosen as NOM model compounds, representing hydrophobic high molar mass and relatively hydrophilic moderate molar mass organic compounds, respectively (Campinas, 2009). Humic acids are mixed compounds and therefore several molar mass values have been reported for AHA: 3070, 4100, 3000-11,000, 14,500 Da (Yamada et al., 2000) and a small fraction above $50 \mathrm{kDa}$ (Hong and Elimelech, 1997). Prior to use, AHA was purified to remove bound iron and decrease the ash content, through hydrochloric acid precipitation, using the method of Hong and Elimelech (1997). AHA stock solution was sequentially filtered through GF$\mathrm{C}(1.2 \mu \mathrm{m})$ and GF-F $(0.7 \mu \mathrm{m})$ Whatman filters before being used to prepare the UF feed solutions. AHA and TA solutions with a concentration of $2-4 \mathrm{mgC} / \mathrm{L}$ were prepared with deionised water (DI) to which a background ionic strength (IS) of $2.5 \mathrm{mM}$ was adjusted by $\mathrm{KCl}$ (up to $1 \mathrm{mM} \mathrm{IS}$ ) and $\mathrm{CaCl}_{2} \cdot 2 \mathrm{H}_{2} \mathrm{O}$ (1.5 mM IS) addition. The $\mathrm{pH}$ was corrected to ca. 7 with $\mathrm{KOH}$ and $\mathrm{H}_{2} \mathrm{SO}_{4}$.

Solutions of algal organic matter were also used, both as extracellular organic matter excreted during cyanobacterial growth (EOM) and AOM, which includes EOM and the intracellular organic matter released during cell lysis. A Microcystis aeruginosa culture was used (Pasteur Culture Collection, PCC 7820), which was grown in BG11 medium, at $23-24^{\circ} \mathrm{C}$ under a light regimen of $12 \mathrm{~h}$ fluorescent light, $12 \mathrm{~h}$ dark. Algae were harvested after one month, corresponding to the exponential growth phase. EOM and AOM preparations were adapted from Takaara et al. (2004). For EOM, the culture growth medium (including cells) was sequentially filtered through a $1.2 \mu \mathrm{m}$ glass filter (Whatman, GF-C), a $0.7 \mu$ m glass filter (Whatman, GF-F) and a $0.22 \mu \mathrm{m}$ hydrophilic polypropylene membrane filter (Millipore). The final filtrate was concentrated 10 -fold in a rotary evaporator and stored at $4{ }^{\circ} \mathrm{C}$ until use. For AOM, harvested cells (suspended in growth medium) were destroyed by ultrasonic treatment $(10 \mathrm{~W}, 10 \mathrm{~min}, 6 \times)$ and two freezing-thawing cycles. The residuals from cell lysis (in the growth medium) were submitted to the filtration sequence previously described for $\operatorname{EOM}(1.2 \mu \mathrm{m} ; 0.7 \mu \mathrm{m}$, $0.22 \mu \mathrm{m})$ and the final filtrate was stored at $4{ }^{\circ} \mathrm{C}$ until use. Specific volumes of EOM and AOM final filtrates were used to prepare the UF feed solutions with a total organic carbon concentration of ca. $4 \mathrm{mgC} / \mathrm{L}$. Given the high content of salts in EOM solutions, no further salts were added, besides the $\mathrm{pH}$ adjustment to ca. 7. In AOM solutions, the conductivity was completed to ca. $300 \mu \mathrm{S} / \mathrm{cm}$ with $\mathrm{KCl}$ and the $\mathrm{pH}$ was adjusted to 7 .

\subsection{UF membrane and PAC}

UF experiments used a hollow-fibre cellulose acetate membrane from Aquasource (inside-out configuration). This UF hydrophilic membrane has a cut-off of $100 \mathrm{kDa}$ and a hydraulic permeability of $250 \mathrm{~L} /\left(\mathrm{h} \mathrm{m}^{2}\right.$ bar) (manufacturer data). The module has 16 fibres, $1.1 \mathrm{~m}$ length and $0.93 \mathrm{~mm}$ internal diameter, with a total surface area of $0.05 \mathrm{~m}^{2}$. The manufacturer recommends a maximum UF pressure of $1.5 \mathrm{bar}$ and a maximum backflushing pressure of 2.5 bar.

The module was mounted in a bench-scale apparatus including a feed tank (FT), a positive displacement pump, two manometers (P1, P2), one flow meter (Flm), a permeate tank (PT) and the valves and tubing involved in the backwashing and in the recirculating loop (V1-V5) (Fig. 1).

PAC/UF experiments used commercially available Norit SA-UF PAC, a highly mesoporous carbon, with a point of zero charge of 9.6 (Campinas, 2009). Its low average particle diameter $(6 \mu \mathrm{m})$ makes it suitable for circulating within the narrow UF hollow-fibres. 


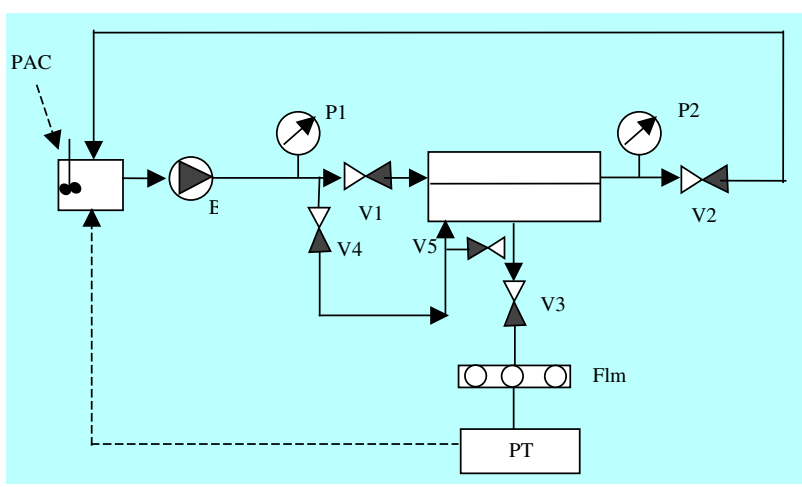

Fig. 1 - Flow diagram of UF apparatus (FT - stirred feed tank; B - positive displacement pump; P - manometers; Flm - flow meter; PT - permeate tank; V1, V4, V5 - valves for backwashing; V2 - concentrate valve; V3 - permeate valve).

\subsection{UF experiments}

All the UF experiments were performed in a cross-flow filtration mode. The module was operated under the inside-out configuration during the filtration cycles and membrane flushing, and under outside-in flow during backwashing. Prior to its first use and before each UF experiment, the membrane was washed, flushed and compacted with DI until achieving a steady permeate flux, at the pressure and cross-flow velocity (CFV) values to be used in the experiments.

Two different types of fouling runs were performed at a constant transmembrane pressure of 0.65 bar and at a $0.5 \mathrm{~m} / \mathrm{s}$ CFV, corresponding to a Reynolds number of 463 at $20^{\circ} \mathrm{C}(1 \mathrm{~m} / \mathrm{s}$ was tested only once): (i) time-depending fouling runs, with the concentrate and the permeate being recycled back to the feed tank during $2 \mathrm{~h}$; (ii) concentration-time-depending fouling runs, with the concentrate being recycled to the feed tank and the permeate being discarded until reaching a predetermined water recovery rate (WRR, defined as the ratio between the permeate and the initial feed volumes). The positive displacement pump provided the necessary pressure and recirculation, and a variable-frequency drive allowed adjusting the CFV in the hollow-fibres. Permeate flow rate and temperature were periodically measured and, whenever necessary, transmembrane pressure was adjusted by manual control of the concentrate valve.

During the time-depending fouling runs, permeate samples were collected at given time intervals (after $30 \mathrm{~min}, 1$ and $2 \mathrm{~h}$ of filtration). During the concentration-time-depending fouling runs, the permeate was discarded and when the predefined WRR was achieved (0\%, 66\% and 90\%), it was recycled to the feed tank during $5 \mathrm{~min}$, after which samples of the feed and the permeate were taken.

In PAC/UF experiments, PAC was directly added to the feed tank that was continuously stirred at $150 \mathrm{rpm}$. The total mass of PAC was always added at the beginning of the filtration cycle, and was only discarded at the end of the run.

At the end of each experiment, membranes were backwashed and flushed. Backwashing lasted $1 \mathrm{~min}$ with a $5 \mathrm{mg} / \mathrm{L}$ $\left(\right.$ as $\mathrm{Cl}_{2}$ ) sodium hypochlorite solution to inhibit the biological activity on the UF system, and flushing was performed with deionised water during $3 \mathrm{~min}$.

Normalised flux, as a function of time (in time-depending fouling runs) or WRR (in concentration-time-depending fouling runs), was used as the membrane fouling indicator. Normalised fluxes were calculated as the ratio of solution flux over the pure water flux before starting the run. All flux values were corrected to a constant temperature $\left(20^{\circ} \mathrm{C}\right)$ using Crozes et al. (1997) equation, $J_{20}=J_{\mathrm{T}} \mathrm{e}^{-0.0239(\mathrm{~T}-20)}$, which is based on the variation of water viscosity with temperature, and where $\mathrm{J}_{20}$ is the flux $\left(\mathrm{L} /\left(\min \mathrm{m}^{2}\right)\right)$ at $20^{\circ} \mathrm{C}, \mathrm{T}$ is the temperature $\left({ }^{\circ} \mathrm{C}\right)$ and $J_{T}$ is the flux $\left(\mathrm{L} /\left(\min \mathrm{m}^{2}\right)\right)$ at temperature $\mathrm{T}$.

Mass-balance equations were applied to compute the percentage of solute adsorbed. The general equation derived to all UF runs (time-depending fouling runs, concentrationtime-depending fouling runs and constant flow runs) is:

$\%$ Adsorbed $=\frac{\left(\mathrm{V}_{0} \mathrm{C}_{0}+\mathrm{QtC}-\mathrm{V}_{\mathrm{f}} \mathrm{C}_{\mathrm{f}}-\sum_{\mathrm{i}=1}^{4} \mathrm{Q}_{\mathrm{pi}} \mathrm{t}_{\mathrm{i}} \mathrm{C}_{\mathrm{pi}}\right)}{\left(\mathrm{V}_{0} \mathrm{C}_{0}+\mathrm{QtC}-\sum_{\mathrm{i}=1}^{4} \mathrm{Q}_{\mathrm{pi}} \mathrm{t}_{\mathrm{i}} \mathrm{C}_{\mathrm{pi}}\right)} \times 100 \%$

where $V_{0}$ and $C_{0}$ are the initial feed volume $(\mathrm{L})$ and concentration $(\mathrm{mg} / \mathrm{L})$, respectively; $Q$ is the feed flow ( $\mathrm{L} / \mathrm{min}$ ) (makeup to balance the permeate out flow), $t$ and $C$ are the associated feed pumping time $(\mathrm{min})$ and concentration $(\mathrm{mg} / \mathrm{L}) ; \mathrm{V}_{\mathrm{f}}$ and $C_{f}$ are the final volume (L) and concentration (mg/L); $Q_{p i}, t_{i}$ and $C_{\mathrm{pi}}$ are the permeate flow (L/min), pumping time (min) and concentration $(\mathrm{mg} / \mathrm{L})$. The equation simplifies according to the experiment, e.g. in the concentration-time-depending fouling runs, QtC does not apply and $\sum_{i=1}^{4} Q_{p i} t_{i} C_{p i}$ simplifies to $\sum_{i=1}^{3} V_{p i} C_{p i}$, where $V_{p i}$ is the permeate volume (L).

\subsection{Analytical methods}

Samples were analysed for $\mathrm{pH}$ at $20^{\circ} \mathrm{C}$ (WTW $340 \mathrm{pH}$ meter), electrical conductivity at $25^{\circ} \mathrm{C}$ (Crison GLP 32 conductimeter), turbidity (HACH $2100 \mathrm{~N}$ nephelometer of high resolution, 0.001 NTU), total and dissolved organic carbon (TOC, DOC) (measured as non-purgeable organic carbon by high temperature combustion method in a Shimadzu TOC 5000A) and/or UV absorbance (UV/vis spectrophotometer, Beckman DU 640B) at $215 \mathrm{~nm}$ and $254 \mathrm{~nm}$, whenever applicable depending on the objective of the experimental run. The DOC concentration and the UV absorbance were both measured on filtered samples ( $0.45 \mu \mathrm{m}$ acrodisks), and TA and AHA concentrations in single-solute solutions were computed from calibration curves against $U_{215 n m}$ and $U_{254 n m}$, respectively. The nature of NOM was assessed through $\mathrm{UV}_{254 \mathrm{~nm}}$ absorbance and SUVA parameter, computed by $\mathrm{UV}_{254 \mathrm{~nm}} / \mathrm{DOC}$.

\section{Results and discussion}

\subsection{UF fouling potential of NOM surrogates}

Concentration-time-depending fouling runs were performed with single-solute solutions of AHA and TA, and with an AHA and TA mixture (with ca. $2.5 \mathrm{mg} / \mathrm{L}$ each) to investigate the individual and combined effects of hydrophobic high molar 
mass and relatively hydrophilic moderate molar mass NOM fractions on the UF membrane fouling. Data are depicted on Fig. 2.

A moderate and rather similar flux decline with WRR was observed for AHA, TA and the mixture of both. Normalised flux decreased from $90 \%$ at $0 \%$ WRR to ca. $70 \%$ (AHA) and ca. $80 \%$ (TA and TA + AHA) at 90\% WRR (Fig. 2, left). However, these results were biased by an artefact developed during the concentration runs (evidenced by the DI trend and most likely related to membrane reversible compaction, a limitation of the experimental apparatus), that accounted for ca. half of the overall flux decline exhibited with these NOM solutions, throughout the entire WRR range tested. Data also show that AHA and TA did not interact to produce stronger foulant behaviour.

TA rejection was quite high (ca. $80 \%$ ) for WRR up to $66 \%$ and decreased to ca. $60 \%$ for $90 \%$ WRR, due to a decrease in the feed concentration and a fairly constant permeate quality (Fig. 2, centre). Since TA is much smaller than the membrane cut-off (1.7 kDa vs. $100 \mathrm{kDa})$ size exclusion/steric hindrance does not apply. On the other hand, the water background ionic strength attenuates potential electrostatic repulsions within (intramolecular) or between (intermolecular) TA molecules and between TA molecules and the membrane. TA adsorption must therefore dominate rejection. Its contribution was computed by mass-balance (Eq. (1)) and yielded $16 \mathrm{mg}$ TA adsorbed during the concentration-time-depending fouling run, i.e. $95 \%$ of the available mass. In UF runs performed at constant flow (data not depicted) TA rejection was also high and relatively constant ( $78 \pm 4 \%$, duplicate runs), and the mass-balance indicated that $70 \%$ of the available mass was adsorbed during the 1-h runs (Campinas, 2009). Crozes et al. (1993) also obtained a significant flux decline (80\%) with both hydrophobic and hydrophilic membranes, caused by the adsorption of high concentration ( $15 \mathrm{mg} / \mathrm{L})$ of tannic acid.

AHA was less effectively rejected than TA for all WRR and the rejection increased from ca. $51 \%$ to $62 \%$ with WRR (Fig. 2, right). During constant flow runs (data not shown) AHA rejection was kept constant ( $71 \pm 2 \%$, duplicate runs) (Campinas, 2009).

Due to its wide molar mass range, AHA rejection may be due to sieving, steric hindrance or adsorption. Although the fouling mechanisms were not studied, the enhancement of AHA rejection with WRR is probably explained by the pore constriction caused by AHA adsorption to the porous surface and/or by the additional sieving provided by the AHA deposits onto the membrane surface, as observed by others (Schäfer et al., 2000; Yuan and Zydney, 2000). Moreover, the flux decline especially evident at the higher solute concentrations (Fig. 2, left) also agrees with a combined effect of concentrationpolarisation, pore constriction/pore blockage and cake layer formation (Schäfer et al., 2000; Yuan and Zydney, 2000).

A mass-balance derived for AHA showed that $83 \%$ of the available mass was actually adsorbed during concentrationtime-depending runs and $43 \%$ during constant flow runs. These results point out the importance of the adsorption phenomenon for AHA, although to a lower extension than for TA (at $90 \%$ WRR, TA feed concentration is half the value at $0 \%$ WRR, whereas for AHA it is 1.3 the value at $0 \%$ WRR). Recent results from kinetic fouling models suggest that in UF membrane fouling there is a transition from internal pore adsorption to pore blocking and latter to cake development (Katsoufidou et al., 2005; Costa et al., 2006).

\subsection{UF fouling potential of algal organic matter}

In addition to allochthonous NOM (humic and tannic acids), autochthonous NOM derived from cyanobacteria was investigated. Cyanobacterial blooms seasonally challenge drinking water treatment due to the massive input of cells and also the release of algogenic organic matter (AOM and EOM) into the water, causing many problems including poor settling, filter clogging, tastes and odours, disinfectant consumption and production of undesired disinfection by-products. Surveys of many fresh cyanobacterial blooms have shown that up to $50-70 \%$ of them are toxic (cyanotoxins) and that one of the most commonly occurring toxic genera is Microcystis, in particular, the species M. aeruginosa (Campinas, 2009).

Time-depending fouling runs were performed with EOM and AOM and, for comparison purposes, also with AHA and TA. Since similar initial TOC concentrations were applied, these four assayed waters enabled the study of NOM characteristic effects rather than the overall concentration (Table 1).

The uppermost values of SUVA belong to AHA, indicating a high degree of conjugation including aromatic carbon, with higher molar mass and hydrophobicity. TA solution has intermediate SUVA values and algal derived organic matter (EOM and AOM) has low SUVA values. These findings are in agreement with Her et al. (2004) and Henderson et al. (2008) AOM characterisation: SUVA values below $1.65 \mathrm{~L} /(\mathrm{mgC} \mathrm{m})$,
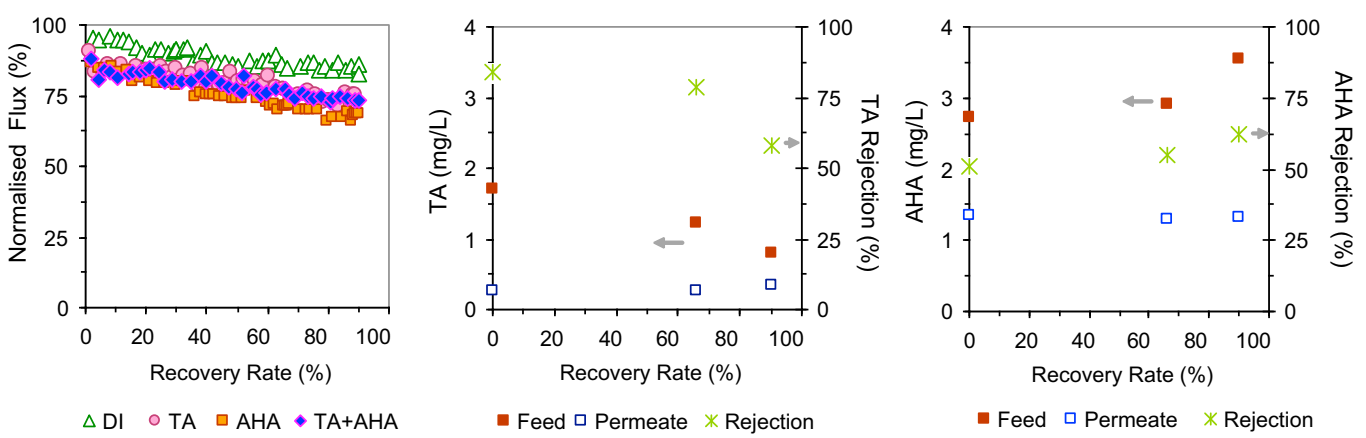

Fig. 2 - Concentration-time-depending fouling runs with NOM model compounds: normalised flux (left), feed and permeate quality, and rejection of TA (centre) and AHA (right) (ca. $2.5 \mathrm{mg} / \mathrm{L}$ each NOM surrogate, $2.5 \mathrm{mM}$ IS background electrolyte). 
Table 1 - Characteristics of the NOM solutions.

\begin{tabular}{lcccc}
$\begin{array}{l}\text { NOM } \\
\text { solutions }\end{array}$ & $\mathrm{pH}$ & $\begin{array}{c}\text { Conductivity } \\
(\mu \mathrm{S} / \mathrm{cm})\end{array}$ & $\begin{array}{c}\text { TOC } \\
(\mathrm{mgC} / \mathrm{L})\end{array}$ & $\begin{array}{c}\text { SUVA } \\
(\mathrm{L} /(\mathrm{mgC} . \mathrm{m}))\end{array}$ \\
\hline AHA & 7.2 & 284 & 3.9 & 6.7 \\
TA & 7.3 & 285 & 3.7 & 4.6 \\
EOM & 7.2 & 831 & 4.5 & 1.3 \\
AOM & 7.2 & 288 & 3.7 & 1.0 \\
\hline
\end{tabular}

corresponding to a dominance of the hydrophilic fraction (57\% or more) over the hydrophobic fraction of NOM (26\%).

Henderson et al. (2008) characterised the EOM extracted from four algal species, including $M$. aeruginosa, during the exponential and the stationary growth phases. They concluded that EOM was dominated by hydrophilic polysaccharides and hydrophobic proteins. During the stationary phase, the M. aeruginosa EOM had a bimodal distribution with $55 \%$ greater than $30 \mathrm{kDa}$ (with $46 \%$ higher than $500 \mathrm{kDa}$ ) and $38 \%$ smaller than $1 \mathrm{kDa}$. Also, about $72 \%$ of total carbohydrates and $52 \%$ of total proteins were above $100 \mathrm{kDa}$, meaning that most of the high molar mass EOM was carbohydrates and proteins. The protein/carbohydrate ratio was 0.31 during the exponential phase and 0.6 during the stationary phase, demonstrating that the amount of proteins relative to carbohydrates doubled with age. Her et al. (2004) also found a greater portion of proteins, mainly of high molar mass (>100 kDa) contained in the IOM (intracellular organic matter) compared to the EOM fraction. The AOM solution has the contribution of both extra- and intracellular organic matter, so it is expected to have a composition similar to EOM during the stationary phase, though with a stronger contribution from cell lysis. According to the previous characterisation, the AOM solution used in the present experiments is likely composed of two fractions: a high molar mass fraction $(>100 \mathrm{kDa})$ dominated by hydrophilic polysaccharides and hydrophobic proteins, and a low molar mass fraction $(<1 \mathrm{kDa})$. As to the EOM solution, it should have a similar composition, but with greater carbohydrates/DOC ratio and with some minor portion of hydrophobic proteins.

The normalised flux and respective TOC and UV rejections obtained in the time-depending fouling runs with TA, AHA, AOM and EOM are depicted on Fig. 3.

The EOM was found to have the most significant impact on membrane fouling, exerting a flux decline of $21 \%$ after $2 \mathrm{~h}$ of operation, slightly higher than the AOM-driven flux decline (18\%) and further distant from AHA (12\%) and TA (10\%) driven flux declines. The higher fouling potential of hydrophilic NOM, like that prevalent with the AOM and EOM fractions studied (SUVA of 1.0 and $1.4 \mathrm{~L} /(\mathrm{mgC} \mathrm{m})$ ), has already been referred by several authors (Her et al., 2004; Lee et al., 2006; Zularisam et al., 2007). Moreover, the EOM run resulted in a more severe membrane fouling than the AOM run, a feature that must not be associated only with the type of organic substances given the much higher salt content of EOM solution with similar TOC concentration.

In fact, during the 2-h runs, the EOM presented the lowest adsorption percentage, $17 \%$ of the available mass, compared to $22 \%$ for $\mathrm{TA}, 25 \%$ for $\mathrm{AHA}$, and $27 \%$ for $\mathrm{AOM}$ (values computed from the mass-balance Eq. (1)). Regarding TOC rejections, algogenic organic matter presented lower values than NOM surrogates (Fig. 3, right). Also, $\mathrm{UV}_{254 \mathrm{~nm}}$ rejections were much lower for EOM and AOM (particularly for the former), most probably due to the fact that polysaccharides have low UV absorbance and the aromatic tryptophan-like proteins have low absorbance at $254 \mathrm{~nm}$ (Henderson et al., 2008). These results show that TOC and $U_{254 n m}$ are not good indicators of membrane fouling by algal matter, as concluded by Her et al. (2004) and Zularisam et al. (2007).

NOM aggregation, complexation and precipitation phenomena driven by the multivalent ions ( $\mathrm{Ca}, \mathrm{Mg}, \mathrm{Fe}, \mathrm{Mn}$, $\mathrm{Zn}, \mathrm{Cu}$ ) present in the assayed waters (as well as in natural waters) arise as the main factor for EOM fouling. The interactions between polysaccharide-type compounds and multivalent cations must produce a denser fouling layer resulting in an increased overall resistance to water permeation. Similar results were found by Jermann et al. (2007) and Katsoufidou et al. (2007) in UF studies with alginate (a typical model polysaccharide used as EOM surrogate) in the presence of calcium.

\subsection{UF fouling potential of PAC}

The impact of PAC addition on UF performance was evaluated in concentration-time-depending fouling runs. PAC was added to deionised water with $2.5 \mathrm{mM}$ background IS $\left(\mathrm{KCl}+\mathrm{CaCl}_{2}\right)$ at a concentration of $5 \mathrm{mg} / \mathrm{L}$. The runs were carried out using two CFV, $0.5 \mathrm{~m} / \mathrm{s}$ (used in all previous runs) and $1.0 \mathrm{~m} / \mathrm{s}$. Normalised fluxes of PAC/UF runs and those of
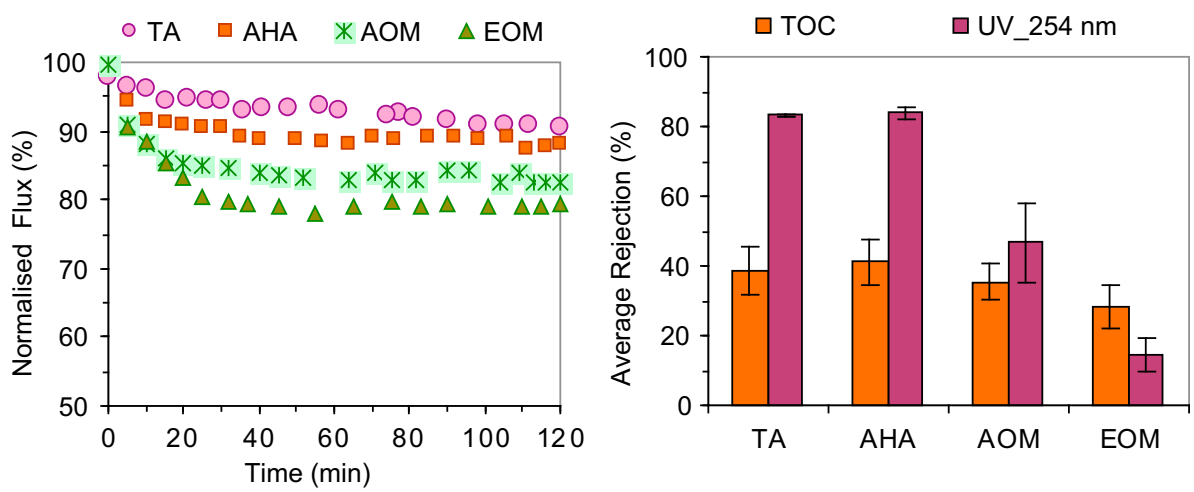

Fig. 3 - Normalised flux (left) and average rejection of organic matter (right) during time-depending fouling runs with different NOM (error bars represent standard deviations). 


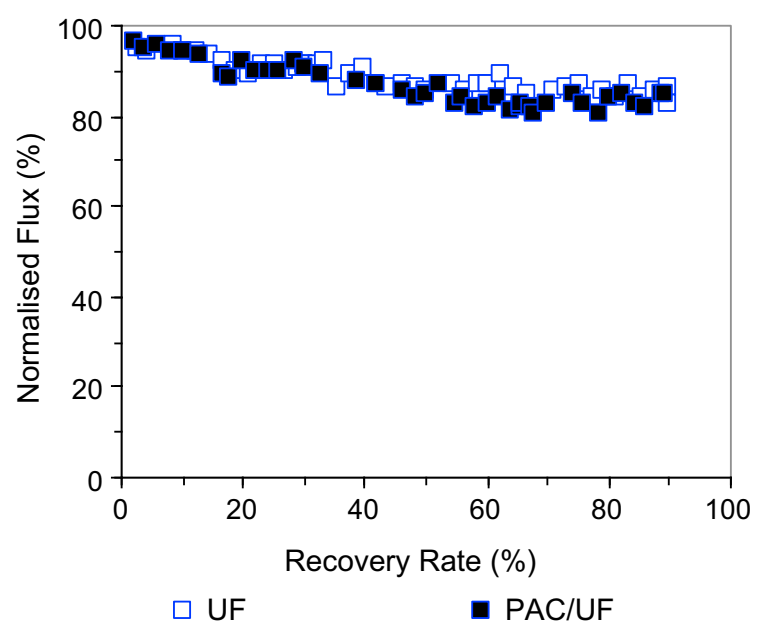

Fig. 4 - Normalised flux during UF and PAC/UF concentration-time-depending fouling runs (UF: no PAC addition; PAC/UF: 5 mg/L PAC addition).

analogous UF runs (with no PAC addition) are presented in Fig. 4, as a function of WRR.

The data demonstrate that PAC alone does not affect the permeate flux of a hydrophilic UF membrane (the curves with and without PAC completely overlap), as found by Lin et al. (1999), Yiantsios and Karabelas (2001), Li and Chen (2004) and Mozia et al. (2005). It seems that the PAC particles are large enough ( $6 \mu \mathrm{m}$ average diameter) to avoid membrane pore blocking. PAC should deposit on the membrane surface, but must form a porous layer that allows the passage of water without an increasing resistance. The deposition of the PAC particles depends on the convective flux and shear forces created by the cross-flow velocity. For the laminar conditions tested (resembling the hydrodynamic conditions at which the industrial UF plants are usually operated), no advantage was observed in performing runs at higher velocities and a similar flux decrease pattern was observed for CFV of $0.5 \mathrm{~m} / \mathrm{s}$

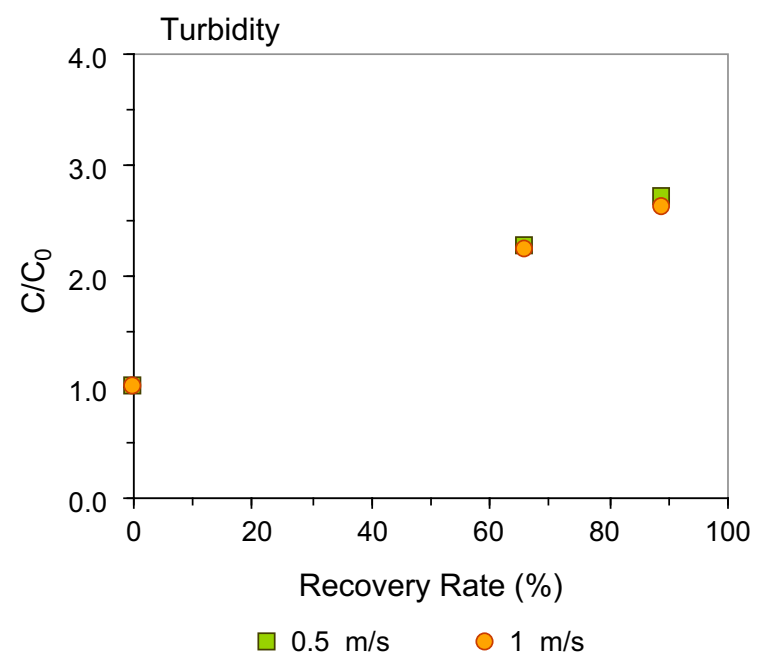

Fig. 5 - Normalised turbidity of PAC/UF feed during the concentration-time-depending fouling runs at two crossflow velocities ( $5 \mathrm{mg} / \mathrm{L} \mathrm{PAC}$ ).
(Reynolds number of 463 , at $20^{\circ} \mathrm{C}$ ) and $1.0 \mathrm{~m} / \mathrm{s}$ (Reynolds number of 926).

Fig. 5 displays the normalised turbidity of PAC/UF feed during the concentration-time-depending runs. The higher CFV did not yield a higher feed normalised turbidity, indicating a similar PAC deposition rate. The permeate turbidity never exceeded 0.1 NTU, even when the feed turbidity reached 7.5 NTU. Hence, UF membrane ensured an effective PAC retention.

Crozes et al. (1997) concluded that CFV particularly matters for high membrane flux. Their results revealed that at $35 \mathrm{~L} /$ $\left(\mathrm{h} \mathrm{m}^{2}\right)$ the flux was CFV independent, whereas at $110 \mathrm{~L} /\left(\mathrm{h} \mathrm{m}^{2}\right)$ a CFV of $0.9 \mathrm{~m} / \mathrm{s}$ was not enough to avoid PAC particles deposition, and the same behaviour was found by Matsui et al. (2001). Even with a CFV above $1 \mathrm{~m} / \mathrm{s}$ the PAC was recycled as a suspension only for a short period of time (Matsui et al., 2001). Both laminar velocities used in the present UF experiments $(0.5 \mathrm{~m} / \mathrm{s}$ and $1.0 \mathrm{~m} / \mathrm{s})$ were thus most probably able to maintain only a small fraction of PAC in suspension and just for a short period of time. The most cost-effective CFV of $0.5 \mathrm{~m} / \mathrm{s}$ was therefore used in the following experiments.

\subsection{NOM fouling potential in PAC/UF system}

PAC is expected to compete with the UF membrane for the adsorption of NOM compounds that otherwise would adsorb on the membrane, causing its fouling. However, some authors have referred that, although PAC itself does not impose significant membrane fouling, when in the presence of NOM it increases the fouling resistance (Lin et al., 1999; Li and Chen, 2004). NOM is believed to act as a glue that binds the PAC particles to one another and to the membrane surface, enhancing fouling. To investigate the combined effect of PAC with different NOM compounds on the membrane fouling, the time-depending fouling runs presented on Section 3.2 were repeated as PAC/UF, i.e. this time adding $10 \mathrm{mg} / \mathrm{L}$ PAC in the beginning of filtration. The normalised flux and respective TOC and $U_{254 n m}$ rejections are presented on Figs. 6 and 7, respectively. For direct comparison purposes, data from analogous UF runs (Section 3.2) are also shown.

Fig. 6 shows no differences at all of the normalised flux with and without the PAC addition, which indicates that PAC neither promoted nor controlled the membrane reversible fouling. This same trend has already been obtained by other authors (Tomaszewska and Mozia, 2002; Matsui et al., 2006; Mozia et al., 2005). Furthermore, the different characteristics of the NOM used in the experiments, such as the hydrophobic or the hydrophilic character, the higher or the lower protein content or even the higher content of salts (in EOM solutions), did not seem to change the PAC impact on the membrane reversible fouling. Zhao et al. (2005) also concluded that NOM plays a quite limited role on PAC cake formation, while a more relevant effect is due to the combination of metal ions, colloids (especially ferric colloids) and PAC. Further experiments onto this combined effect are necessary.

These NOM-PAC fouling results differ from those obtained by Jermann et al. (2008) with NOM-kaolinite. These authors focused on the mechanistic effects of molecular interactions between inorganic particles (kaolinite) and two NOM fractions of polysaccharides (alginate) and humics (humic acids) in 

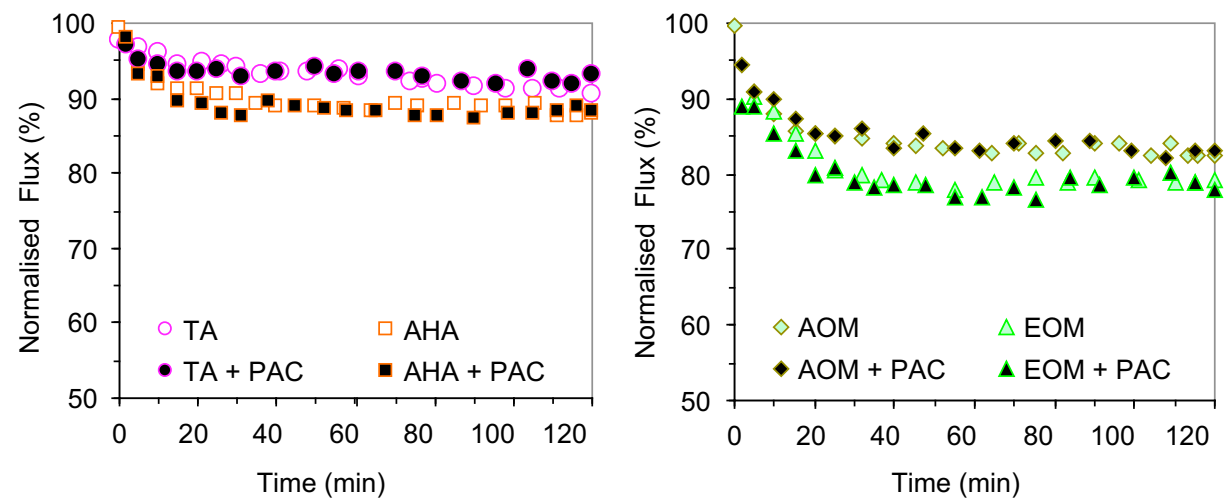

Fig. 6 - Normalised flux during PAC/UF (10 mg/L PAC) and UF time-depending fouling runs with NOM surrogates (left) and algogenic organic fractions (right).

ultrafiltration. They observed a significant synergistic effect during combined NOM-kaolinite fouling explained by NOMparticle interactions developed in the feed solution and during the fouling process (NOM incorporation in the kaolinite fouling layer resulted in a fouling cake of significantly reduced porosity). Nevertheless, depending on their size, particles and colloids may enhance or prevent fouling. According to Schäfer's (2001) survey, particles on the $5-75 \mu \mathrm{m}$ range promoted turbulence and therefore prevented or minimised the nanofiltration membrane fouling, whereas the UF flux decline increased with particle size up to $3 \mu \mathrm{m}$, especially in the $0.2 \mu \mathrm{m}$ range. These observations may explain the different behaviour of Norit SA-UF $(6 \mu \mathrm{m})$ and kaolinite $(0.1-2 \mu \mathrm{m})$ when interacting with NOM.

Results of NOM rejection obtained with and without PAC addition (Fig. 7) indicate a PAC-driven rejection enhancement of AHA and especially TA: 41\% (AHA) and 38\% (TA) average TOC rejection without PAC addition vs. 54\% (AHA) and $68 \%$ (TA) with $10 \mathrm{mg} / \mathrm{L}$ PAC; 83\% average $\mathrm{UV}_{254 \mathrm{~nm}}$ rejection of both AHA and TA without PAC vs. 89\% (AHA) and 92\% (TA) with PAC. For AHA and TA, $U_{254 n m}$ rejections far exceeded the TOC rejections, revealing that the $U_{254 n m}$ absorbing compounds are preferentially removed.

PAC has lesser impact on the removal of algal organic matter, though to differing degrees for AOM and EOM. PAC enhanced the TOC rejection of $\mathrm{AOM}$ (35\% vs. 55\%) and had no significant effect on the $\mathrm{UV}_{254 \mathrm{~nm}}$ absorbing substances of AOM or on TOC and $U_{254 n m}$ rejections of EOM constituents. The higher removal of AOM compared to EOM is probably associated with the presence of more hydrophobic compounds in the former fraction, which explains the PAC-driven improvement of TOC rejection. Apparently, PAC was not able to adsorb the highly hydrophilic compounds of EOM (only expressed by the overall content as TOC, since $U_{254 n m}$ is a very poor indicator for polysaccharides and aromatic tryptophan-like proteins) and as such did not improve the membrane reversible fouling.

\subsection{Membrane cleaning}

Membrane fouling may be reversible, and thus be easily cancelled by membrane backwashing, or irreversible, requiring chemical cleaning of the membrane. The control of irreversible fouling is particularly important for reducing the operating costs of the membrane process. A very important aspect of this study was therefore to find if PAC has any effect on membrane irreversible fouling.

The recovery of the membrane permeability to pure water was computed as $J_{1} / J_{0}$, where $J_{1}$ is the pure water flux after backwashing and $J_{0}$ is the initial pure water flux. Fig. 8 shows $J_{1} / J_{0}$ values after the time-depending fouling experiments with AHA, TA, EOM and AOM, with and without PAC addition.

Results show that, without PAC, the membrane fouling by AHA, AOM and EOM was completely reversible, whereas for TA the permeability was not fully recovered (there was a $10 \%$ loss), indicating a membrane irreversible fouling by tannic
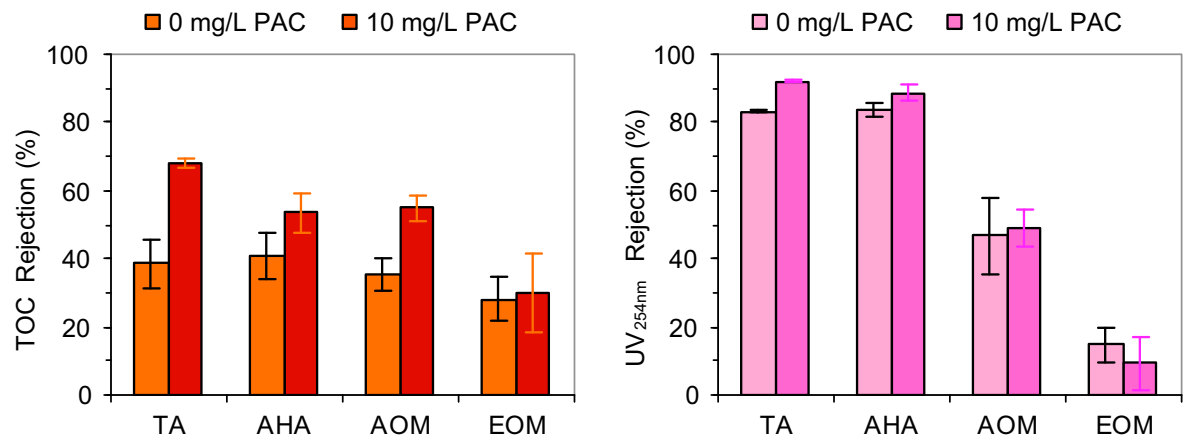

Fig. 7 - TOC (left) and UV $\mathrm{UV}_{254 \mathrm{~nm}}$ (right) rejections of NOM surrogates and algogenic organic fractions during PAC/UF (10 mg/L PAC) and UF fouling runs (error bars represent standard deviations). 


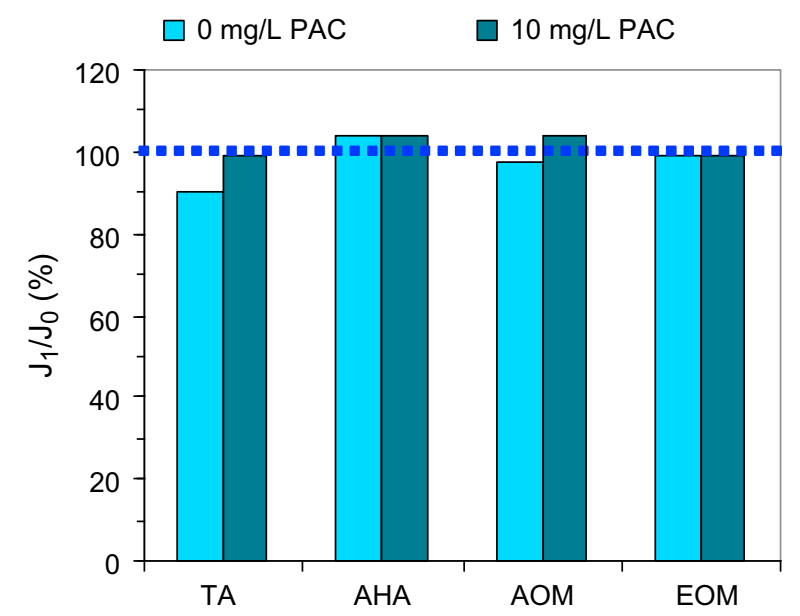

Fig. 8 - Recovery of membrane pure water permeability after time-depending fouling runs with different NOM and with/without PAC addition $\left(V_{1}-\right.$ pure water flux after backwashing; $J_{0}$ - initial pure water flux).

acid. Reversible fouling by EOM was also reported by Katsoufidou et al. (2007) in UF studies with sodium alginate in the presence of calcium. TA irreversible fouling coincides with the overall flux decline caused by this solute and indicates its strong adsorption to membrane pores.

With PAC addition, the observed fouling was completely reversible for all solutes, including TA, which is explained by the high adsorption capacity of PAC Norit SA-UF for that compound.

Fig. 9 shows the $J_{1} / J_{0}$ values achieved by different cleaning procedures (based upon 1 load/cleaning cycle) after the UF concentration-time-depending fouling runs with TA.

After the simplest cleaning with deionised water (DI), a permeability loss of $25 \%$ was observed and the usual chemical cleaning with a low dose of sodium hypochlorite $\left(5 \mathrm{mg} / \mathrm{L}\right.$ as $\mathrm{Cl}_{2}$ ) was able to recover only $4 \%$ of the membrane permeability to pure water. This means an irreversible fouling

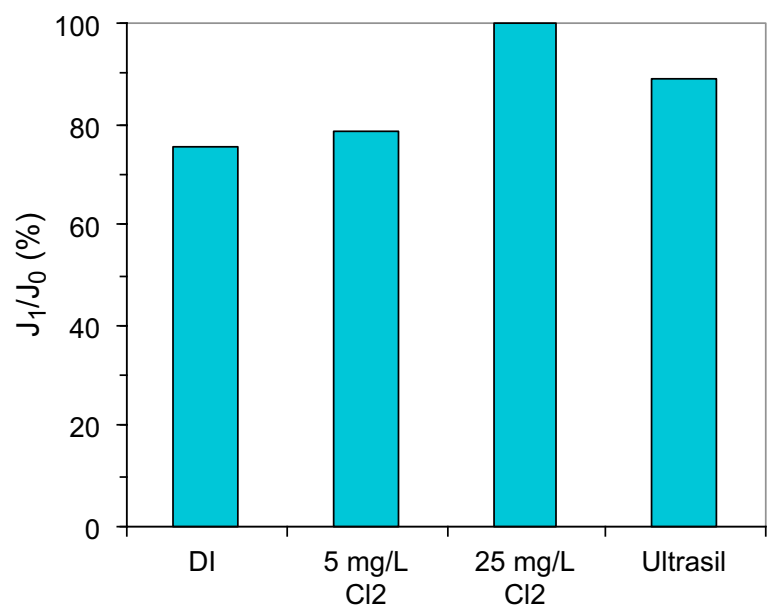

Fig. 9 - Recovery of membrane pure water permeability after the concentration-time-depending fouling runs with TA, using different cleaning procedures $V_{1}$ - pure water flux after membrane cleaning; $J_{0}$ - initial pure water flux). of ca. $21 \%$ in TA concentration experiments. The use of a $0.02 \%$ (w/w) solution of an alkaline detergent (Ultrasil) attenuated half $(52 \%)$ of the TA irreversible fouling and the use of high doses of sodium hypochlorite (minimum of $25 \mathrm{mg} / \mathrm{L}$ as $\mathrm{Cl}_{2}$ ) cancelled all the irreversible fouling. With PAC addition (10 $\mathrm{mg} / \mathrm{L})$, irreversible fouling of the UF membrane during the TA concentration runs decreased to $14 \%$. Furthermore, since the beginning of the PAC/UF experiments, minimal irreversible fouling was observed and the regular use of $25 \mathrm{mg} / \mathrm{L}$ as $\mathrm{Cl}_{2}$ was no longer required, and the full recovery of the membrane water permeability was almost always achieved after a backwash with $5 \mathrm{mg} / \mathrm{L} \mathrm{Cl}_{2}$ and a final flushing with DI. This feature may be explained by the NOM adsorption capacity of PAC and by the relatively loose structure and high porosity of the PAC cake deposited on the membrane, which was therefore easily backwashed. Actually, the membrane backwashing easily removed the PAC cake layer (thin film-like) from the hollowfibres, and the implementation of a quick flush after backwashing further increased the removal of the deposited PAC, as reported by Adham et al. (1991).

\section{Conclusions}

This study investigated the PAC contribution to the NOM fouling control in PAC/UF systems, as well as the foulant behaviour of the PAC itself on the reversible and irreversible fouling of a hydrophilic UF membrane. Humic acid (AHA), tannic acid (TA), and algogenic organic matter (AOM) and its extracellular fraction (EOM) were studied since the PAC/UF application for cyanobacterial-rich water treatment (a worldwide environmental health issue) is envisaged.

The data from UF time-depending fouling runs indicated that the EOM had the most significant impact on membrane fouling followed by AOM, AHA and TA. The higher fouling potential of EOM seemed to be mainly associated with polysaccharide-like substances interaction with multivalent ions, resulting in dense fouling layers. The results also showed that TOC and $\mathrm{UV}_{254 \mathrm{~nm}}$ are not adequate to assess membrane fouling potential by algal organic matter.

UF concentration-time-depending runs with $5 \mathrm{mg} / \mathrm{L}$ PAC Norit SA-UF at $0.5 \mathrm{~m} / \mathrm{s}$ and $1 \mathrm{~m} / \mathrm{s}$ cross-flow velocity showed that the UF membrane effectively retained the fine PAC particles, whereas PAC did not affect the permeate flux of the hydrophilic membrane. Moreover, both laminar velocities studied were unable to avoid the deposition of a loose and highly porous PAC cake on the membrane surface, and there is therefore no advantage in using the least cost-effective $(1 \mathrm{~m} / \mathrm{s})$ velocity.

The PAC addition $(10 \mathrm{mg} / \mathrm{L})$ neither attenuatted nor exacerbated the flux decline during the UF time-depending fouling runs with each of the NOM solutions tested. The different hydrophobic/hydrophilic character, protein and salts content of the NOM solutions did not change the PAC impact on the membrane reversible fouling. PAC increased AHA, TA and hydrophobic AOM rejections (with subsequent benefits in disinfection by-products control), but was apparently ineffective for adsorbing the highly hydrophilic EOM, and as such did not improve the EOM-driven membrane reversible fouling. 
While no PAC effect was found on the membrane reversible fouling by AHA, AOM and EOM, PAC was able to control the irreversible fouling caused by tannic acid (a solute able to penetrate and adsorb within the membrane pores but to which the studied PAC has a high adsorption capacity), avoiding the need for severe membrane cleaning (with $25 \mathrm{mg}$ $\mathrm{Cl}_{2} / \mathrm{L}$ ) after the UF runs.

\section{Acknowledgments}

The authors would like to thank the Portuguese Science and Technology Foundation for providing a Ph.D. scholarship to Margarida Campinas (BD/10356/2002). Special thanks are also addressed to Águas do Algarve, S.A. (Portugal) for partially funding this project.

\section{R E F E R E N C E S}

Adham, S., Snoeyink, V., Clark, M., Bersillon, J.L., 1991. Predicting and verifying organics removal by PAC in an ultrafiltration system. Journal of American Water Works Association 12, 81-91.

Campinas, M., 2009. Removal of Cyanobacteria and Cyanotoxins from Drinking Water by Powdered Activated Carbon Adsorption/Ultrafiltration. Ph.D. thesis in Environmental Sciences and Technologies, Universityof Algarve, Faro, Portugal.

Cho, J., Amy, G., Pellegrino, J., 2000. Membrane filtration of natural organic matter: comparison of flux decline, NOM rejection, and foulants during filtration with three UF membranes. Desalination 127, 283-298.

Costa, A., De Pinho, N., Elimelech, M., 2006. Mechanisms of colloidal natural organic matter fouling in ultrafiltration. Journal of Membrane Science 281, 716-725.

Crozes, G., Anselme, C., Mallevialle, J., 1993. Effect of adsorption of organic matter on fouling of ultrafiltration membranes. Journal of Membrane Science 84, 61-77.

Crozes, G., Jacangelo, J., Anselme, C., Laîné, J., 1997. Impact of ultrafiltration operating conditions on membrane irreversible fouling. Journal of Membrane Science 124 (1), 63-76.

Henderson, R., Baker, A., Parsons, S., Jefferson, B., 2008. Characterisation of algogenic organic matter extracted from cyanobacteria, green algae and diatoms. Water Research 42 (13), 3435-3445.

Her, N., Amy, G., Park, H.R., Song, M., 2004. Characterizing algogenic organic matter (AOM) and evaluating associated NF membrane fouling. Water Research 38, 1427-1438.

Hong, S., Elimelech, M., 1997. Chemical and physical aspects of natural organic matter (NOM) fouling of nanofiltration membranes. Journal of Membrane Science 132 (2), 159-181.

Jermann, D., Pronk, W., Meylan, S., Boller, M., 2007. Interplay of different NOM fouling mechanisms during ultrafiltration for drinking water production. Water Research 41 (8), 1713-1722.

Jermann, D., Pronk, W., Kägi, R., Halbeisen, M., Boiler, M., 2008. Influence of interactions between NOM and particles on UF fouling mechanisms. Water Research 42 (14), 3870-3878.

Jones, K., O'Melia, C., 2000. Protein and humic acid adsorption onto hydrophilic membrane surface: effects of $\mathrm{pH}$ and ionic strength. Journal of Membrane Science 165, 31-46.

Katsoufidou, K., Yiantsios, S., Karabelas, A., 2005. A study of ultrafiltration membrane fouling by humic acids and flux recovery by backwashing: experiments and modeling. Journal of Membrane Science 266, 40-50.
Katsoufidou, K., Yiantsios, S., Karabelas, A., 2007. Experimental study of ultrafiltration membrane fouling by sodium alginate and flux recovery by backwashing. Journal of Membrane Science 300, 137-146.

Konieczny, K., Klomfas, G., 2002. Using activated carbon to improve natural water treatment by porous membranes. Desalination 147, 109-116.

Lee, N., Amy, G., Croué, J.P., 2006. Low-pressure membrane (MF/UF) fouling associated with allochthonous versus autochthonous natural organic matter. Water Research 40, 2357-2368.

Lee, C., Bae, S., Han, S., Kang, L., 2007. Application of ultrafiltration hybrid membrane processes for reuse of secondary effluent. Desalination 202, 239-246.

Li, C.W., Chen, Y.S., 2004. Fouling of UF membrane by humic substances: effects of molecular weight and powder-activated carbon (PAC) pre-treatment. Desalination 170, 59-67.

Lin, C.F., Huang, Y.J.-, Hao, O., 1999. Ultrafiltration processes for removing humic substances: effect of molecular weigth fractions and PAC treatment. Water Research 33 (5), 1252-1264.

Lin, C.F., Liu, S.H., Hao, O., 2001. Effect of functional groups of humic substances on UF performance. Water Research 35 (10), 2395-2402.

Matsui, Y., Yuasa, A., Colas, F., 2001. Effect of operational modes on the removal of a synthetic organic chemical by powdered activated carbon during ultrafiltration. Water Science and Technology: Water Supply 1 (5/6), 39-47.

Matsui, Y., Sanogawa, T., Aoki, N., Mima, S., Matsushita, T., 2006. Evaluating submicron-sized activated carbon adsorption for microfiltration pretreatment. Water Science and Technology 6 (1), 149-155.

Mozia, S., Tomaszewaska, M., Morawski, A., 2005. Studies on the effect of humic acids and phenol on adsorption-ultrafiltration process performance. Water Research 39, 501-509.

Schäfer, A., Fane, A., Waite, T., 2000. Fouling effects on rejection in the membrane filtration of natural waters. Desalination 131, 215-224.

Schäfer, A., 2001. Natural Organics Removal Using Membranes. Principles, Performance and Cost. Technomic Publication, Lancaster, USA.

Takaara, T., Sano, D., Konno, H., Omura, T., 2004. Affinity isolation of algal organic matters able to form complex with aluminum coagulant. Proceedings of the IWA 4th World Water Congress, Marrakech, Marrocos, 19-24 September.

Tomaszewska, M., Mozia, S., 2002. Removal of organic matter from water by PAC/UF system. Water Research 36, 4137-4143.

Yamada, E., Doi, K., Okano, K., Fuse, Y., 2000. Simultaneous determinations of the concentration and molecular weight of humic substances in environmental water by gel chromatography with a fluorescence detector. Analytical Sciences 16 (2), 125-129.

Yamamura, H., Kimura, K., Watanabe, Y., 2007. Mechanism involved in the evolution of physically irreversible fouling in microfiltration and ultrafiltration membranes used for drinking water treatment. Environmental Science and Technology 41, 6789-6794.

Yiantsios, S., Karabelas, A., 2001. An experimental study of humic acid and powdered activated carbon deposition on UF membranes and their removal by backwashing. Desalination 140, 195-209.

Yuan, W., Zydney, A., 2000. Humic acid fouling during ultrafiltration. Environmental Science and Technology 34, 5043-5050.

Zhao, P., Takizawa, S., Katayama, H., Ohgaki, S., 2005. Factors causing PAC cake fouling in PAC-MF (powdered activated carbon-microfiltration) water treatment systems. Water Science and Technology 51 (6-7), 231-240.

Zularisam, A., Ismail, A., Salim, M., Sakinah, M., Ozaki, H., 2007. The effects of natural organic matter (NOM) fractions on fouling characteristics and flux recovery of ultrafiltration membranes. Desalination 212, 191-208. 